\title{
IMPLEMENTING A BIM COLLABORATIVE WORKFLOW IN THE UK CONSTRUCTION MARKET
}

\author{
NIDAA ALAZMEH, JASON UNDERWOOD \& PAUL COATES \\ School of the built environment, University of Salford, Salford, United Kingdom
}

\begin{abstract}
BIM Level 2, as defined by the UK government, sets out processes and standards that formalise and regulate the collaborative methods for producing, sharing and exchanging information during different stages of any construction project. For overseas organisations that are looking to invest in the UK construction market, they will most certainly need to consider developing their understanding and ability related to BIM in order to enable developing their capability and competency to compete. This paper presents a case study that focuses on the implementation of collaborative based BIM workflow at a large Chinese engineering and construction organisation, which has recently established operations in the UK. The BIM implementation has been achieved under a Knowledge Exchange Partnership framework between the organisation and an academic institution in the UK. The main aim for this partnership project was to transform the organisation's traditional workflow to achieve a BIM based collaborative workflow, and to comply with BIM Level 2 requirements. The case study has been achieved by adopting an action research methodology, whereby the project affiliate was an active part of the implementation project and was managing and coordinating the partnership project between the organisation and academic partner. Results to date from the project will be documented in this paper. This includes highlighting key challenges, adopted strategies and tactics to overcome the obstacles, pockets of improvements and potential areas for future development.
\end{abstract}

Keywords: building information modelling, collaboration, communication, process, information exchange, innovation.

\section{INTRODUCTION}

The number of Chinese companies investing in the UK market is now growing rapidly; this growth is directly linked to the development of a strategic relationship between the UK and the people's republic of China. The operations level in some industries like construction has started with many companies entering the market as operator rather than investor. However, the expansion to the level of operating construction projects will require these organisations to consider and implement some UK specific standards, process and methods that differentiates the UK market from the market in China.

Collaborative production of construction projects is one of the main requirements to achieve BIM Level 2 in the UK. Level 2 BIM has been set by the UK government as mandated for projects funded by the central government. The UK construction strategy 2011 highlights and explains the benefits and the target saving behind the government mandate of BIM [1]. NBS surveys in 2016 indicate the growing and developing awareness within the whole industry regarding BIM requirements [2]. Figures and surveys in the UK and worldwide show the increasing number of companies adopting BIM during the last couple of years. The number is growing considerably as The National BIM Report Survey [2] shows that more than $95 \%$ of practitioners, who are aware of BIM, in the UK are currently using or believe that they will be using BIM within the next 5 years. However, this approach is different from the one adopted in the Chinese construction industry where there is no governmental strategy to promote and demand the implementation of BIM in a nationwide framework. Although some provinces started to encourage the BIM implementation within the industry, there is no sufficient standards or documents that can entirely support that implementation in 
details [3]. One of the main challenges that is facing the adoption of BIM Level 2 is to transform the traditional individual model of producing information to achieve the collaborative model that is described in BIM Level 2 standards [4]. Facilitated by innovative advance technology and software applications, the collaborative workflow needs to set out new processes and methods, that comply with BIM Level 2 standards, and that could be adopted by all project stakeholders as an innovative way of work. These new methods of collaborative work clearly illustrate the importance of Information Technology to support this new workflow. Underwood and Khosrowshahi highlighted the importance of information technology in construction, and stressed that Information Technology is now recognised as a major asset for any business [5]. BIM adopters still need to overcome different challenges and obstacles either technology related, or process and workflows related [6]. Another type of challenge is related to creating and promoting a new culture that emphasises and stresses the collaborative work within an organisation; this cultural change is one of the essential elements to ensure the successful implementation of the collaborative model. Skills shortage presents another main issue that potentially limits the ability of BIM collaborative work within the industry [7], and slows down the movement towards the adoption of BIM.

This paper presents a case study for implementing a BIM-based collaborative workflow through a Knowledge Exchange Partnership project between The University of Salford and BCEGI, UK. The project shows a unique model of transferring and sharing academic knowledge with the industry. The knowledge exchange, in this addressed case, presents one of the successful methods to bring academia and industry together for the benefit of both partners [8]. This model could be used to enhance the universities curriculums with industry-base case studies [9]. Benefits from adopting this partnership model are completely different from providing consultancy, as it is based on a long-term relationship through an associate who is based full time in the partner company. The model also provides a unique opportunity for the knowledge exchange associate to gain the related experience through the company, as well as accessing the scheme related training and development opportunities. The key goal of the project is to develop a collaborative workflow based on BIM Level 2 for the company, and to spread the collaborative culture within the organisation. The project is designed to be delivered in four phases. A related methodology has been developed to meet the requirements of each phase. The project is planned to be achieved within 18 months.

\section{ADOPTED METHODOLOGY}

The case study has been achieved by adopting an action research methodology, whereby the project affiliate was an active part of the implementation project and was managing and coordinating the partnership project between the organisation and academic partner. The organisation, Beijing Construction Engineering Group (BCEGI), has been recently established in the UK as tier 1 contractor in the construction industry. One of the main objectives of the partnership project between The University of Salford and BCEGI is to develop an implementation plan for the company to transform the organisation towards BIM-based collaborative work practice and process, and to meet the requirements of the UK government in terms of BIM. The duration of this project is for 18 months, and the project is divided into four phases.

- Phase one: detailed review and analysis of the organisation's current situation.

- Phase two: develop BIM implementation strategy based on Level 2 BIM processes and requirements.

- Phase three: pilot project BIM implementation.

- Phase four: project review, evaluation and dissemination. 
The scheme of Knowledge Exchange Partnership is managed and monitored by the partnership office at the University of Salford. The partnership office requires regular meetings and reports to address the exact progress and achievements of the project to ensure that the project is in progress to achieve its objectives. The project is now in its final stage. The first, second and third phases have been achieved, and a detailed evaluation to document what has been accomplished is now undertaken. Primary data for the case study has been collected by interviews and observation. A strategy to manage the resistance to change and promote the implementation of BIM collaborative workflows has been established. The adopted methodology for phases one, two and three was mainly based on tackling each of the addressed problems separately to ensure that he root causes are permanently treated [10]. This ensures that the organisation will not face any similar problem in the future as the problems has been permanently treated. The proposed methodology for phase three is based on adopting best practice methods to implement BIM through a pilot project. Phase four method is focus on optimising a critical evaluation to assess impact of the BIM adoption on the pilot project.

\section{PHASE ONE: DETAILED ANALYSIS OF THE ORGANISATION'S CURRENT SITUATION}

\subsection{Introduction}

This phase aims to develop a detailed understanding of the current position in relation to organisational processes, procedures, practices, IT infrastructure and BIM maturity and to fully understand the way in which the organisation performs its business.

\subsection{The adopted process}

Detailed analysis and review regarding the adopted process, workflows, and communication methods was achieved for the first phase of the project. The gathered information was critical in terms of understanding how the company is operating and how BIM can benefit and improve the level of collaboration. The gathered information identified that the company is operating in a traditional method relying on emails and meetings to exchange information. The BIM department already exists in the organisation. However, it is not a part of the project delivery process, and it has been set as a separate department with no responsibility towards the projects. BIM team does not have access to any up to date project information, and they do not have any structured collaboration with the project delivery team.

The current process map of BCEGI (Fig. 1) clearly reflects the low level of collaborative methods incorporated with a high level of sequences in the workflow, the process map clearly reflects that there is no repository adopted to exchange information, and the server is currently used to manually store selected information after each milestone. Design suppliers' information, client information are all to be pushed to BCEGI team using individual methods such as emails or paper submission. Feedback with request of information follows design submissions and is also done individually based on personal emails. Implications of these methods include loss of information, and reworks as information is not consistently available to everyone in the team.

\subsection{Current communication and information exchange model within the organisation}

Communication: The main adopted method for communicating and exchanging information at BCEGI was either face-to-face communicating or emails. At the stage of collecting data for 


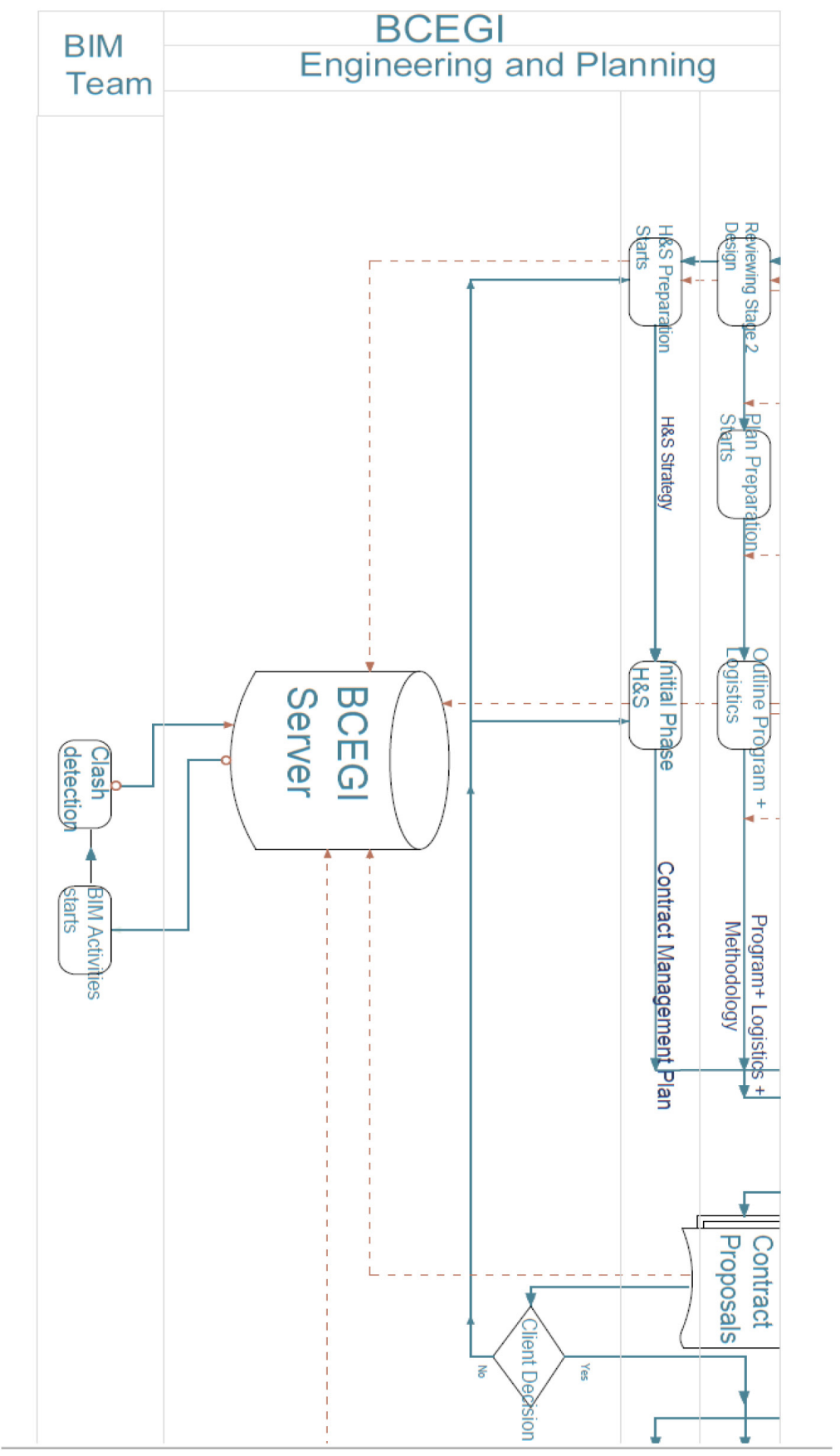

Figure 1: The current adopted BIM process at BCEGI. Source: Author's own construction. 
this case study, this method of communication was not causing major problems as the team was still considered small, and as all project staff were working in the same office. However, as the company is growing rapidly, this individual and unstructured methods of communicating is highly likely to develop and cause major issues mainly related to the lack of up-to-date information, which causes a high level of waste revising reworking. Other issues such as loosing information or will also develop, and will negatively impact the process of project delivery. 2D PDF drawings are used for most types of communication through the project delivery journey, even 3D BIM models are available, and this limits the ability for visually aided communication based on $3 \mathrm{D}$ visualised models.

Additionally, the same method of communication is adopted across all the supply chain. This makes the communication network considerably complicated and unstructured. Accordingly, the risk of information loss during any stage of the project delivery is very high. Figure 2 illustrates the current adopted communication methods at BCEGI, and reflects that individuals are seeking information based on unstructured email or face to face based methods of communication. Exchanging information during the project progress is conducted based on individual means. BCEGI maintains a server which is used to store information at some points of the project delivery. By the time of doing this data collection there was no structured way that mandates holding certain information on the server. As a result, the server was primary to be used to store approved documents or to archive information. Exchanging information with suppliers was based on a similar unstructured process, this method creates a recognised waste as there is a high potential of duplicating the work of sending and receiving information. Figure 3 shows the adopted methods of information exchange at BCEGI.

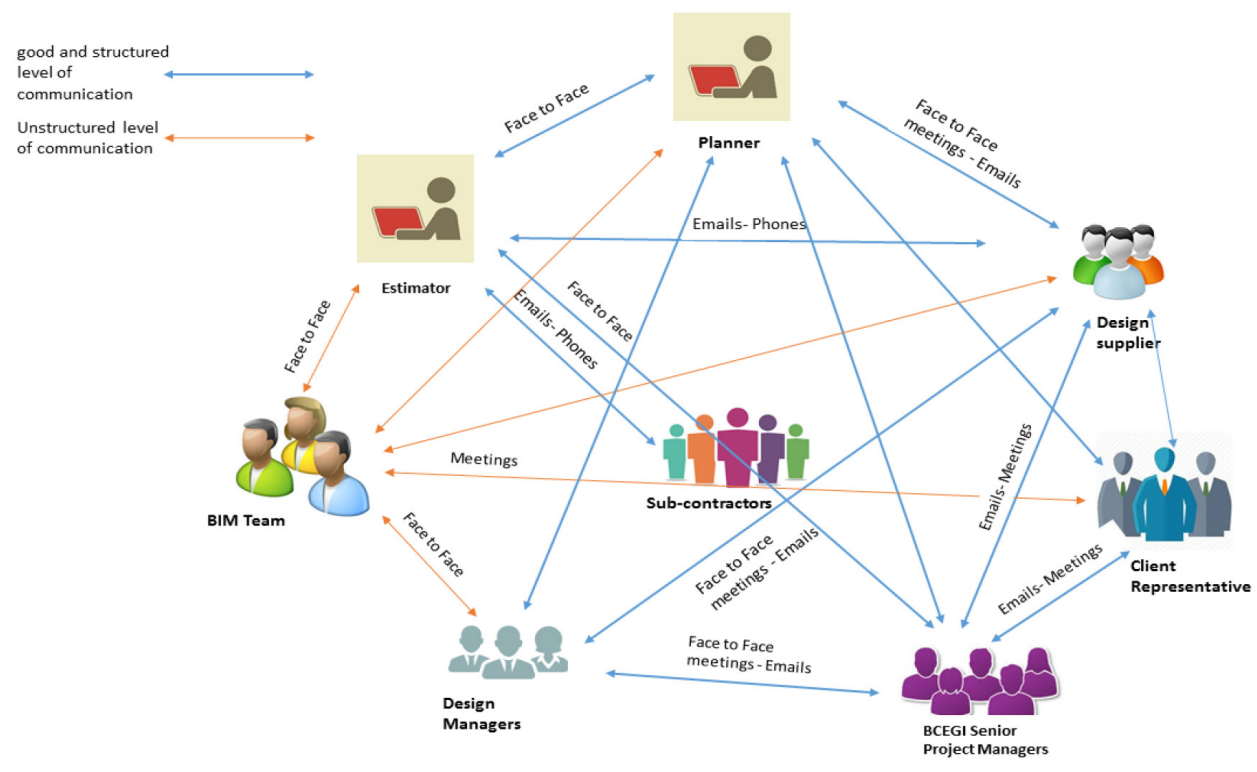

Figure 2: The current adopted communication methods at BCEGI. Source: Author's own construction. 


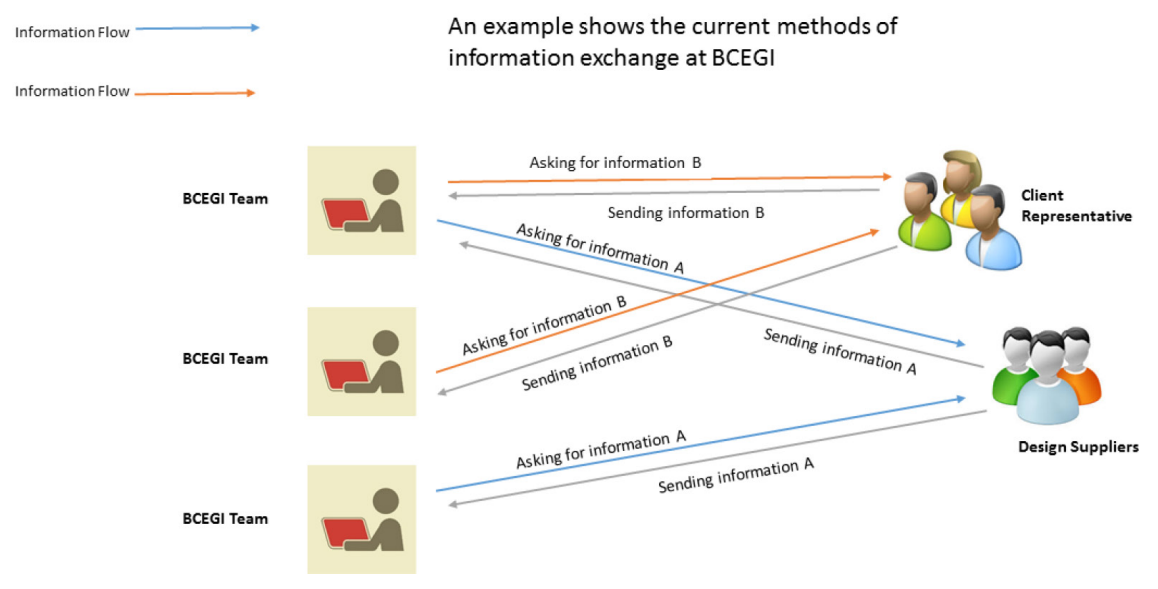

Figure 3: The current adopted information exchange methods at BCEGI. Source: Author's own construction.

\subsection{Problems and challenges addressed in Phase one}

Prior to starting propos and implement an innovative solution, there was an initial need to analyse and document existing problems related to the current traditional workflow. The starting point was to address some essential problems, such as the effectivity of the adopted communication methods and information exchange ways. It was established that solving these problems definitely needs to be one of the goals of proposing any alternative solution. It has also been established that there is a high need to introduce the team to the latest updates in the construction industry in regard to the BIM area and advanced technology. Identified problems include the lack of up-to-date information, the insufficiency in exchanging information across the supply chain, the ignorance of BIM information delivery process, and the limitations of advanced 3D based means of visual communication. Problems and issues have been identified and the related waste have been linked to each problem. This classification of problems and issues in relation with waste enabled the team establishing a vision and determine the future actions to help solve the addressed problems. Visions and actions have been carefully designated to ensure the problem will be solved permanently and the organisation will not face similar problems in the future. The table below presents the main problems in BCEGI that needs to be solved in order to improve collaboration and enhance communication. Figure 4 illustrates the problems and the planned actions to solve them.

\section{PHASE TWO: DEVELOP BIM IMPLEMENTATION STRATEGY PLAN}

\subsection{Introduction}

The strategy for phase two was developed based on the information gathered and analysed in phase one to ensure solving the addressed problems and issues. This phase requires developing a strategy plan to implement BIM collaborative processes and workflows within the current adopted processes in the organisation. The main goal of the developed strategy is to permanently overcome the problems identified in phase one. 


\begin{tabular}{|c|c|c|c|c|}
\hline Problem & Issue & Waste & Vision & Action \\
\hline $\begin{array}{l}\text { No ability to access } \\
\text { any up-to-date } \\
\text { project information }\end{array}$ & $\begin{array}{l}\text { Seeking information is } \\
\text { extremely time consuming, } \\
\text { different naming } \\
\text { conventions are used }\end{array}$ & $\begin{array}{l}\text { Waste of time } \\
\text { seeking updated } \\
\text { information }\end{array}$ & $\begin{array}{l}\text { Build an information } \\
\text { system to keep all } \\
\text { project information } \\
\text { departments }\end{array}$ & $\begin{array}{l}\text { Investigate } \\
\text { possibility for cloud } \\
\text { based information }\end{array}$ \\
\hline $\begin{array}{l}\text { Insufficient } \\
\text { information } \\
\text { exchange with the } \\
\text { supply chain }\end{array}$ & $\begin{array}{l}\text { No agreed and } \\
\text { standardised methods } \\
\text { adopted to exchange } \\
\text { information }\end{array}$ & $\begin{array}{l}\text { Waste of time due to } \\
\text { duplication and } \\
\text { reworks in exchanging } \\
\text { information, risk of } \\
\text { information loss }\end{array}$ & $\begin{array}{l}\text { Investigate the } \\
\text { willingness to } \\
\text { adopt CDE }\end{array}$ & $\begin{array}{l}\text { Start to find out if } \\
\mathrm{CDE} \text { is required for } \\
\text { any project }\end{array}$ \\
\hline $\begin{array}{l}\text { BIM process is not } \\
\text { recognised as an } \\
\text { option for the } \\
\text { delivery process }\end{array}$ & $\begin{array}{l}\text { No enough } \\
\text { awareness of BIM } \\
\text { mandate }\end{array}$ & $\begin{array}{l}\text { Low level of } \\
\text { competency in the } \\
\text { market }\end{array}$ & $\begin{array}{l}\text { Start spreading the } \\
\text { BIM culture within } \\
\text { the company }\end{array}$ & $\begin{array}{l}\text { Organise series of } \\
\text { presentations }\end{array}$ \\
\hline $\begin{array}{l}\text { Limitation to } \\
\text { communication means } \\
\text { as it is done in } 2 \mathrm{D}\end{array}$ & $\begin{array}{l}\text { No utilisation of } 3 \mathrm{D} \\
\text { models as a visual means } \\
\text { for communication }\end{array}$ & $\begin{array}{l}\text { Waste of time trying } \\
\text { to understand and } \\
\text { solve design issues }\end{array}$ & $\begin{array}{l}\text { Cultivate the role of } \\
\text { BIM models as a better } \\
\text { way to communicate }\end{array}$ & $\begin{array}{l}\text { Investigate the } \\
\text { ability to implement } \\
\text { 4D planning }\end{array}$ \\
\hline
\end{tabular}

Figure 4: The identified problems, visions, and actions. Source: Author's own construction.

\subsection{Develop BIM implementation strategy:}

Based on information collected and analysed in Phase one of the project, the project team highlighted how BIM could provide some very good solutions for the problems identified in Phase one. Furthermore, reviewing phase one data reflects that implementing standards, processes, and technology mandated by BIM Level 2 could be one of the recognised gains for the business as a Tier 1 contractor operating in the UK. In addition to meet the UK government requirements for Level 2 BIM (Government Construction Strategy, 2011), the company will be able to benefit from managing and delivering their projects in a collaborative 3D BIM environment.

\subsection{The adopted philosophy:}

A top-down approach based on a 'pilot project approach' to manage the changes effectively was the adopted philosophy [11] to start the implementation of a BIM collaborative approach. This approach involves all senior management team within the organisation and emphasises their role to drive for the desired changes. Spreading the knowledge of BIM, as well as getting the team to be up-dated with the latest innovative methods adopted in the industry was also one of the key points of the agreed philosophy. The figure below explains different adopted tactics and the targeted benefits and goals. The final target is to resolve problems itemised in phase one. Figure 5 shows the adopted tactics and the targeted benefits.

\section{PHASE THREE: PILOT PROJECT BIM IMPLEMENTATION}

\subsection{Introduction}

The strategy for phase three is to implement the plan, which has been developed for phase two in a pilot project. This phase requires implementing the collaborative process, based on 
Tactic

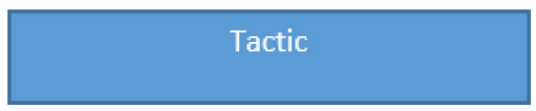

Create a debate within the organisation about the need for an innovative collaborative workflow

Get project team to be involved in the BIM adoption planning and decisions

Spread the awareness regarding the latest BIM related innovation methods recently emerged in the construction industry
Target benefits

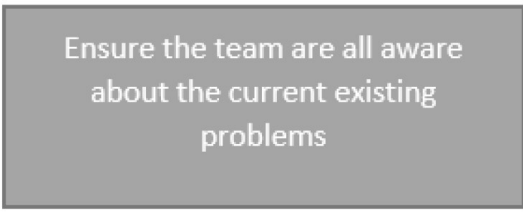

Ensure the team will decide the best approach that suit their actual needs

Enable people to understand why they need to make changes and how changes will increase the company's competency

Figure 5: The adopted tactics and the targeted benefits. Source: Author's own construction.

BS1192:2007 [12], into one of the company's project to improve the level of collaboration and information exchange during design, construction, and asset lifecycle stages.

\subsection{The pilot project implementation}

Prior to starting the BIM implementation, it was therefore decided to organise several BIM sessions to present and discuss the potential benefits for the company to start the BIM discussion and highlight the benefits of BIM for the company. BIM training sessions were organised to spread the BIM culture, and bring the awareness regarding BIM. Three sessions have been organised and delivered, the topics are related to BIM Level 2 standards and how these standards could impact manging the supply chain information in a collaborative approach. By the end of the training sessions, it has been proposed to form a BIM committee to be responsible to drive the implementation within the whole organisation. The BIM committee was formally approved and all the senior management team were involved in the committee. Senior management team decided to implement a Common Data Environment (CDE), which is a cloud-based data management system that enables a collaborative work. The implementation of such data management systems is one of the core points for moving towards BIM Level 2 as described by the UK government. The purpose of implementing a CDE for BCEGI was to facilitate a collaborative workflow for one of the projects that the company is working on. Several meetings were held to discuss and decide the best CDE application after attending different demonstration from different providers, after considering the company's criteria Asite has been chosen to be implemented to host all information across BCEGI and its supply chain. 
BS1192:2007+A2:2016 has been presented to the senior management team as one of the pillars of BIM Level 2, and as an approved standard to manage the architectural, engineering, and construction information. The standards sets out the requirements and methods to effectively manage information across the whole supply chain, ensure quality of submitted information and provide required liability to protect originators rights and responsibility [12].

The implementation of the standard required some upskilling and training sessions organised by the software providers company. Additionally it required replacing the traditional role of document controller with a new role with emerging requirements related to essential knowledge and previous experience working in a BIM Level 2 environment. The new document controller was responsible to start the implementation of a new naming convention that is described in both BS1192:2007+A2:2016, and PAS 1192-2:2013. The next stage was to provide related training to BCEGI's supply chain, assessment for each individual supplier has been achieved to identify the actual needs of each supplier. Customised sessions for supply chain were arranged and held at BCEGI offices. Related process maps and protocols have been published to support the implementation, the published protocols and workflows have been later included in BCEGI's BIM Execution Plan Template to be used in any new projects.

In parallel, the Planning Lead for the company decided to push forward to investigate about the 4D planning and simulation. The purpose was to improve the communication methods with the client and local authorities, and to improve the planning of site activities and logistics. Software demonstration were arranged and different software packages were examined to determine suitability. Based on the requirements and information gathered from the planning team, Synchro has been chosen to be implemented for the purpose of 4D simulation. The company also recruited a BIM technical expert to take the responsibility of producing 4D simulations using Synchro. The first simulations have been accomplished as a pilot project and the simulation was used to enhance site communication and logistics coordination.

\section{PHASE FOUR: PROJECT REVIEW, EVALUATION AND DISSEMINATION}

\subsection{Introduction}

The strategy for phase four involves evaluating what has been planned and implemented in the previous phases of the projects. Primary data for phase four were collected through interviews with BCEGI senior management team.

\subsection{Project review and evaluation}

Project review has been undertaken by the Knowledge Exchange Affiliate. Data to review and evaluate what has been achieved were gathered through interview BCEGI senior management team who were involved in the project. Analysing interviews data clearly reflects a good level of satisfactory towards the project' outcomes. Senior management team expressed that implementing the collaborative workflow has considerably improved and ease the information exchange and communication methods across the company's supply chain. Additional benefit related to quality management has also been highlighted by the senior managers. These benefits are mainly as a result of automatically linking quality checklists and approval gates to the implemented data management system. Improvement gains related to BIM 


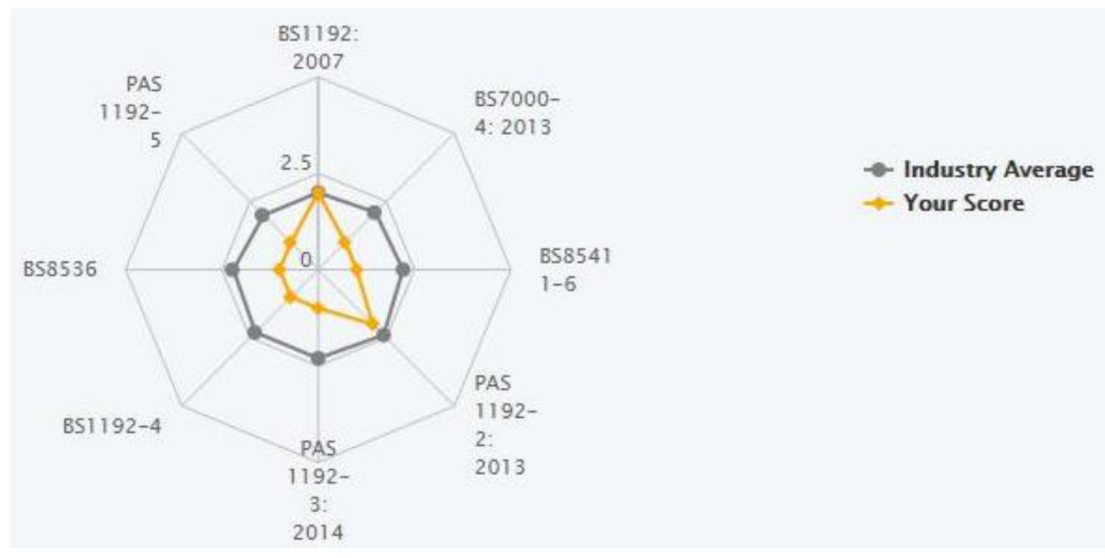

Figure 6: The BIM maturity assessment at BCEGI. Source: Author's own construction.

capability have been modelled and defined using one of the available BIM maturity models. The model noticeably reflects that the company has moved towards BIM Level 2 standards; however, it is still below the average achieved level across the UK industry. Figure 6 illustrates the BIM maturity Level at BCEGI at stage four of the knowledge exchange project.

The new model of sharing and exchanging information through the implemented common data environment has replaced the previous method of exchange through emails. The new model has created a secured and trusted source of information that is substantially essential to record and hold the project's information. The figure below shows an example for sharing design information according to the implemented exchange and approval method based on BS1192:2007+A2:2016. Impacts of the adoption of a collaborative workflow has been widely recognised across the business, identifies wastes such as reworks, resubmission of information, or waste of time to access updated information are all solved with the implementation of a cloud based information management platform. Managing supply chain information submission and exchange is currently smooth and well established, Approval of submitted documents to control quality is now linked to the electronic information management system. Additionally, adopting the naming convention described in BS1192:2007+A2:2016 was essential to enabled different parties who can access the Asite platform to find and track information, it also facilitated controlling the information flow throughout the project progress.

\section{CONCLUSIONS}

Building Information Modelling is an emerging paradigm that is gradually influencing the traditional methods and process across the construction industry. BIM requires developing new processes, adopting new technologies, and inspiring people with a new working culture. Implementing an innovative workflow, which is based on the collaborative approach has been successfully established within BCEGI, this implementation has been supported by a business decision adopting a top-down approach. Overcoming the resistance to change has been managed by establishing the required related BIM knowledge among the team.

Partnership projects between the academic sector and the construction industry present an effective and unique model widely embrace to facilitate the adoption of BIM. On one hand, 
this collaborative model of knowledge exchange positively leverage the relationship between universities and construction organisations for the benefits of both sides. On the other hand, this model provides the opportunity for overcoming the shortage of skills in the construction by enabling fresh candidates to enter the market. Moreover, the knowledge exchange partnership model is aimed to develop the internal capability of the partner organisation rather than aiming to provide temporal consultancy.

This paper documented a partnership project between The University of Salford and BCEGI, UK. The partnership project was proposed and designed with the aim of supporting the organisation to transform their traditional workflow towards an innovative collaborative model. In addition, the project aimed to spread the BIM collaborative culture across the team accompanied with a good level of awareness regarding the latest BIM related policies published by the UK government. The partnership project was designed and delivered through four phases. This paper explained the journey across the four phases and highlighted different adopted strategies and philosophy to achieve the project' goals and objectives. The first phase of the project completed a detailed analysis that showed the adopted processes and workflows within the organisation. Second phase of the project proposed a BIM based collaborative workflow to be adopted. Third phase of the project detailed how the proposed plan was implemented in a pilot project. The project is currently in its fourth phase, and the knowledge exchange project team are evaluating and assessing the project achievements, and the up-to-date impact of the implemented processes on the organisation.

Latest results and findings from the project indicates how the organisation has moved forwards in terms of their BIM journey towards achieving BIM Level 2. In depth, this reflects that BS1192:2007, which is designed to support the collaborative workflow, has been fully implemented within the company's processes and became their business as usual way of working. In addition, achieving other BIM Level 2 related standards has also been achieved, this includes BS1192:2007+ A2:2016, PAS1192-2. Benefits from the recent adopted technology base processes has been realised within the senior leadership management team. The relationship between The University of Salford and BCEGI is moving forward and a new partnership project, which is to build on this project, is to follow this current partnership to carry on the BIM implementation journey at BCEGI.

\section{REFERENCES}

[1] Government Construction Strategy 2011, UK government construction strategy, available at: https://www.gov.uk/government/uploads/system/uploads/attachment_data/ file/61152/Government-Construction-Strategy_0.pdf. (accessed 21 December 2016).

[2] NBS, NBS National BIM Report 2016, UK2016, available at: https://www.thenbs.com/ knowledge/national-bim-report-2016. (accessed 20 January 2017).

[3] Bo, J., Khan, R. R. A., Vian, A., \& Zhijun, C. (2015). BIM Implementation in China: A Case Study Approach. International Conference on Information Technology and Management Innovation (ICITMI 2015).

[4] BIM Level 2, available at: http://bim-level2.org/en/. (accessed 12 March 2017).

[5] Underwood, J. \& Khosrowshahi, F., ITC expenditure and trends in the UK construction industry in facing the challenges of the global economic crisis. Journal of Information Technology in Construction (ITcon), 17, pp. 25-42, 2012.

[6] Eastman, C.M., BIM handbook: a guide to building information modelling for owners, managers, designers, engineers, and contractors, John Wiley \& Sons Inc.:Hoboken, New Jersey, 2011. 
[7] CIOB, Skills shortage still a concern for faltering construction industry. The Charted Institute of Building, 2016, available at: http://www.ciob.org/media-centre/news/skillsshortages-still-concern-faltering-construction-industry. (accessed 10 March 2017).

[8] Lambert, R., Lambert review of business-industry collaboration. Final Report, 2003 December, HMSO, ISBN 0-947819-76-2.

[9] Coates, P., Arayici, Y. \& Koskela, L.J., Using the Knowledge Transfer Partnership model as a method of transferring BIM and Lean process related knowledge between academia and industry: A Case Study Approach. International Conference of Ecobuild America: Sustainable, High Performance \& Technology Solutions for Built Environment, Washington DC, USA, 2010.

[10] Sobek II, D.K. \& Smalley, A., Understanding A3 thinking: a critical component of Toyota PDCA management system. CRC Press: Boca Raton, FL, 2011.

[11] Arbulu, R. \& Zabelle, T., Implementing Lean In Construction How to Succeed. Paper presented at the international group for lean construction conference (IGLC 2006) Santiago, Chile, 2006.

[12] BS 1192:2007+A2:2016 Collaborative production of architectural, engineering and construction information. Code of practice, 2016, available at: http://shop.bsigroup. com/forms/PASs/BS-1192-2007/. (accessed 07 March 2017). 